\title{
A PHYSICALLY-BASED APPROACH FOR EVALUATING THE HYDRAULIC INVARIANCE IN URBAN TRANSFORMATIONS
}

\author{
MATTEO BOTTICELLI ${ }^{1}$, ROBERTO GUERCIO $^{1}$, ROBERTO MAGINI $^{1} \&$ ROSARIO NAPOLI $^{2}$ \\ ${ }^{1}$ D.I.C.E.A., Sapienza University of Rome, Italy. \\ ${ }^{2}$ CREA-AA, Council for Agricultural Research and Economics.
}

\begin{abstract}
Transformation of urban areas satisfies hydraulic invariance (HI) if the maximum flow rate outgoing the area stays unchanged. The HI can be respected by dimensioning appropriate water storage volumes or low impact developments (LID) to balance the soil sealing and ground levelling effects. In order to comply with HI, some Italian regional legislation and river basin authority provide for the creation of storage tanks whose volume must be estimated through simple conceptual rainfallrunoff models. In this work a physically based approach for evaluating $\mathrm{HI}$ is proposed. It is based on interpolating the results from a large number of hydraulic simulations conducted using FullSWOF, which is an open source code developed by the University of Orléans. In this software the shallow water equations are solved using a finite volume scheme and friction laws and infiltration models are included. Simulations have been carried out considering the effect of three properties of the area, that is: the saturated hydraulic conductivity of soil, the slope of ground surface and the standard deviation of ground elevation around the mean level. Using the results, interpolating laws for the peak discharge and the critical rainfall duration as function of the three basin parameters have been derived. A parametric hydrograph as a function of the basin parameters and rainfall duration is defined and a HI evaluation method based on routing the parametric hydrograph is proposed. The results from this approach have been compared with those from non-physically based methods currently used, such as the direct rainfall approach and the linear reservoir approach. The comparison shows that the difference between these conceptual methods with that one proposed here is strongly dependent on the runoff coefficient value. It is also not possible to predict whether they are conservative or not.

Keywords: Hydraulic invariance, Land planning, Soil properties, Sustainable urban drainage systems, Urban Transformation
\end{abstract}

\section{INTRODUCTION}

After a rainfall event on a basin, two main phenomena determine flood's magnitude: infiltration and routing of the surface outflow. In rural basins the infiltration rate is high due to the absence of artificial ground cover and water flows slowly in intricated, braided paths. This results in low peak discharge and high duration hydrographs. Urban transformations increase imperviousness and regularize the ground producing high velocities and low infiltration losses. This results in large peak discharge and flash floods after sudden rain. This condition can be critical for urban drainage systems, increasing hydraulic risk and causing depletion of the aquifer. In the last decades the urbanization without any hydrological land planning caused significant damages and then measures to guarantee hydrogeological asset sustainability are needed. This can be done both dimensioning water storage with the purpose to temporary stock the rainfall water volume and then to release it gradually or allowing it to infiltrate in proper areas in which sustainable urban drainage systems (SuDs) measures, such as rain gardens and wetlands, are available. 


\section{REGULATORY FRAMEWORK}

In Italy the need to define methods that guarantee the principle of $\mathrm{HI}$ in urban planning interventions has been prompted by frequent and sudden flooding events due to the climate and to the high anthropization of the territory. Imperviousness and surface regularization that follow urban development highly contribute to these events. Existing drainage systems are often designed using simple methods, with the purpose to collect water from rainfalls with low return time and are not thought to protect against extreme events. Therefore, in some basin plans and regional laws since the beginning of this millennium the principle of hydraulic invariance is introduced in the context of urban transformation projects.

A first effort to produce a mathematical method to call "invariant" a land use change in terms of water discharge was done by Pistocchi [1] in 2001 and applied in Regione Emilia Romagna. This author proposed a simplified equation based on a constant udometric coefficient (i.e., the contribution of the basin unitary area to the formation of peak discharge) computed with the linear reservoir method, which allows to design the water storage volume to cut down the increased runoff coefficient following transformation:

$$
w=w_{0}\left(\frac{\varphi}{\varphi_{0}}\right)^{\frac{1}{1-n}}
$$

where

- $\mathrm{w}$ is the designed water storage volume

- $\mathrm{w}_{0}$ is the water storage volume of the area before transformation

- $\varphi_{0}$ and $\varphi$ are runoff coefficients before and after transformation

- $\mathrm{n}$ is the exponent of the intensity, duration, frequency (IDF) power law.

The runoff coefficients are computed as the weighted average with the percentage of permeable and impervious area. Eqn (1) is obtained by imposing the matching between the udometric coefficient for critical rainfall conditions before and at the end of transformation. But, this equation does not consider the possibility that, once the maximum allowed flow rate after the transformation has been defined, there may be longer rain durations for which the ante-operam peak discharge is exceeded and then a larger storage volume could be required. The Romagna river basins' Authority in 2003 inserts eqn (1) in the basin plan, assuming prefixed values of $\phi_{0}, \phi$ and $\mathrm{w}_{0}$.

Regione Veneto provides two methods based on reservoir flood routing: the linear reservoir method and the direct rainfall method. Both the approaches evaluate the maximum volume that exceeds the peak discharge of ante-operam condition. They are still based on simple rainfall-runoff conceptual models, and they use the runoff coefficient as the only parameter to treat infiltration losses. Moreover, runoff coefficient values that can be found in technical literature usually focus on differences between types of land cover, usually there is no adequate classification based on soil and subsoil textural and granular properties. Other Italian regions or river basin authorities follow similar approaches based either on the equation (1) or on the concept of flood routing.

\section{MATHEMATICAL MODEL}

In order to contribute to the Italian regulatory framework proposing a more physically based approach, in the present paper a HI criterion is provided using a numerical integration of the 
shallow water equations. The software used is FullSWOF 2D, an open source code developed by the University of Orléans.

FullSWOF stands for Full Shallow Water equations for Overland Flow (Delestre et al. [2]). The code solves numerically the following 2D shallow water system:

$$
\left\{\begin{array}{c}
\partial_{t} h+\partial_{x}(h u)+\partial_{y}(h v)=R-I \\
\partial_{t}(h u)+\partial_{x}\left(h u^{2}+\frac{g h^{2}}{2}\right)+\partial_{y}(h u v)=g h\left(S_{0 x}-S_{f x}\right) \\
\partial_{t}(h v)+\partial_{x}(h u v)+\partial_{y}\left(h v^{2}+\frac{g h^{2}}{2}\right)=g h\left(S_{0 y}-S_{f y}\right)
\end{array}\right.
$$

where

- $\mathrm{u}$ and $\mathrm{v}$ are the velocity components

- $\mathrm{h}$ is the water height

- $\mathrm{R}$ and I are rain intensity and infiltration rate

- $\mathrm{S}_{0 \mathrm{x}}$ and $\mathrm{S}_{0 \mathrm{y}}$ are the ground slope components

- $\mathrm{S}_{\mathrm{fx}}$ and $\mathrm{S}_{\mathrm{fy}}$ are the friction terms components

FullSWOF computes infiltration using the Green-Ampt modified model (Green and Ampt [3], Mein and Larson [4]). Infiltration is considered with a bi-layer model (Esteves et al. [5], Hillel e Gardner [6], Delestre [7]). The upper layer is characterized by the thickness $Z_{c}$ and the permeability $K_{c}$, while the second layer, having an infinite depth, by the permeability $\mathrm{K}_{\mathrm{s}}$.

FullSWOF integrate the shallow water equations with a "well-balanced" finite volume method based on a hydrostatic reconstruction (Audusse et al. [8], Bouchut [9]). The hydrostatic reconstruction allows to reconstruct new variables to be used in the numerical flux definition. It is designed to achieve good properties such as water mass conservation, water height positivity preservation and preservation of lake at rest equilibrium.

\section{A PHISICALLY-BASED HI APPROACH}

In order to define a HI physically based method a large number of hydraulic simulations have been carried out on a one-hectare sample area in the municipality of Fiumicino (Rome), considering constant hyetographs of different duration. The resulting hydrographs have been parameterized as function of:

- Duration of the rainfall

- Slope of the ground

- Standard deviation (std dev) of the ground elevation

- Saturated hydraulic conductivity

Once the parametric hydrograph has been defined, a storage flood routing is applied. The aim is to find the rainfall duration giving the maximum storage volume, once the maximum outflow allowed from the area is given. In fact, the results from FullSWOF show that the shape of the hydrographs is strictly dependent on the duration of the rain. 
Using the FullSWOF results, interpolating laws for the peak discharge and the critical rainfall duration as function of the three basin parameters have been also derived.

\subsection{The parametric hydrograph}

The outflow hydrographs show common features:

- Sigmoid-shaped rising limb

- Peak flow at the end of rainfall (no lag time)

- Exponential-shaped falling limb

Hence the following mathematical function representing the hydrograph has been chosen:

where

$$
\left\{\begin{array}{c}
Q=a \cdot \tanh (b \cdot t+c)+a \text { for } t \leq t_{d} \\
Q=Q\left(t_{d}\right) e^{d \cdot t} \text { for } t>t_{d}
\end{array}\right.
$$

- $\mathrm{Q}$ is the flow rate

- $t_{d}$ is rainfall duration

- a, b, c and d are four coefficients function of the hydraulic conductivity, the average slope of the area, the standard deviation of ground elevation and the rainfall duration.

Rising limb and falling limb are separately interpolated using the MATLAB Curve Fitting Tool, in order to find the four coefficients for each simulation:

\subsection{The HI criterion}

Once the hydrograph coefficients have been defined, the hydraulic invariance has been evaluated following three steps:

1. Computing the maximum outflow from the area in ante-operam conditions using the hydraulic conductivity, mean basin slope and std dev of ground elevation interpolating laws

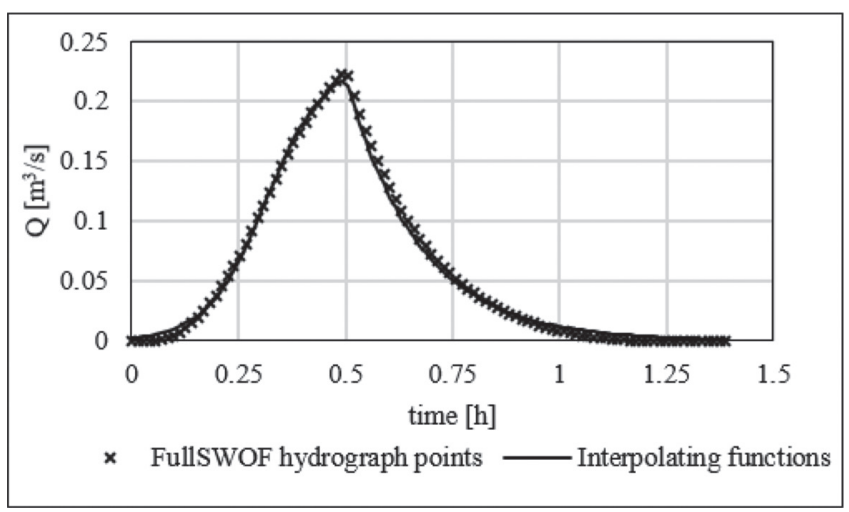

Figure 1: Hydrograph interpolation. 


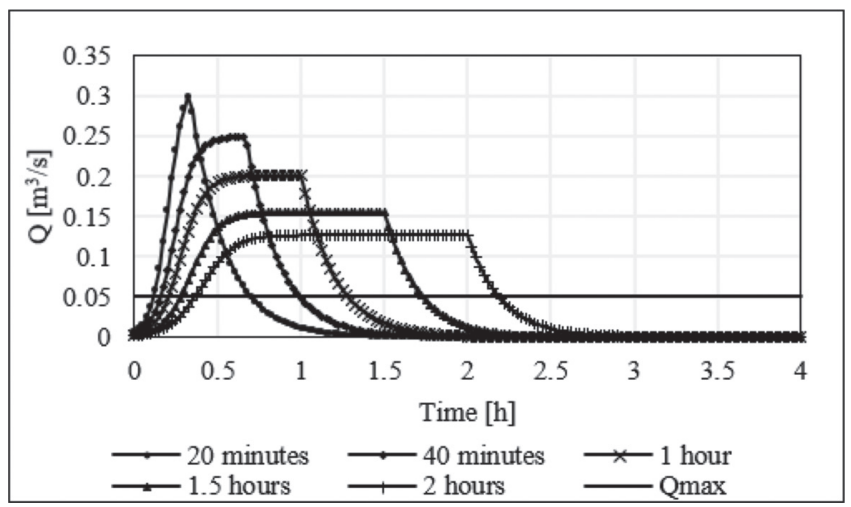

Figure 2: Flood routing-based HI method.

2. Defining the post-operam parametric hydrograph

3. Flood routing with post-operam hydrographs to find the maximum volume exceeding ante-operam peak discharge.

\section{TEST AREA: FIUMICINO}

The previous approach has been applied to the territory of the municipality of Fiumicino. A one-hectare area has been considered for the numerical simulations. Constant hyetographs from a 50 years return time IDF curve have been used. The constant hyetograph has been considered in order to have a better comparison with the conceptual models based HI methods. The 50 years return time is derived by most of the regional and river basin authority laws.

The range of hydraulic conductivity has been defined on the base of Fiumicino soil types, using pedological data provided by CREA, the Council for Agricultural Research and Economics.

In order to establish a relationship between the hydraulic conductivity and the parameters required by FullSWOF, the mean Green Ampt parameters provided by Rawls and Brakensiek [10] were used and the approach proposed by Brevnova [11] was followed. Moreover, an initially fully saturated soil has been assumed. The basin slope range was between $0.05 \%$ and $0.15 \%$, typical of a mainly flat area, such as that of Fiumicino. Flat areas are usually more affected by intensive urban development compared to hilly and mountainous ones where the land cover permeability reduction is less relevant for infiltration losses. The standard deviation of ground elevation well describes the initial abstraction of the area. Here three values of std dev have been considered: $0.0,0.01,0.1$. The parameters used in the simulation are listed in Table 1:

Table 1: Parameters used in the simulations.

\begin{tabular}{lll}
\hline Permeability K & Mean slope I & Std Dev $\sigma$ \\
\hline $\mathrm{m} / \mathrm{s}$ & $\%$ & - \\
\hline $1 \times 10^{-7}$ & 0.05 & 0.00 \\
$1 \times 10^{-6}$ & 0.10 & 0.01 \\
$5 \times 10^{-6}$ & 0.15 & 0.10 \\
$1 \times 10^{-5}$ & - & - \\
\hline
\end{tabular}




\section{SIMULATIONS RESULTS}

Each FullSWOF simulation has produced the hydrograph outgoing the area. A time step of 5 minutes has been used to find the maximum peak discharge for each $\mathrm{K}$, $\mathrm{i}$ and $\sigma$ combination (Fig. 3).

In Fig. 4 the dependence of peak discharge with the hydraulic conductivity at different area slope is represented considering a null value of std dev. In Fig. 5 the same dependence is obtained for std dev equal to 0.1 . We can notice that in the second case the curves are very similar to each other. This means that in highly irregular surface, the mean slope has not a significant role in determining the peak flow.

A further comparison has been made between the peak discharge obtained from FullSWOF and that one from the rational equation. At this aim the time of concentration in the rational equation has been derived using different formulations. The runoff coefficient in the rational equation has been taken from literature according to the hydraulic conductivity of the soil. Figure 6 shows great differences especially for pervious soils, that is for hydraulic conductivity larger than $10^{-5} \mathrm{~m} / \mathrm{s}$ : in particular in this range the rational equation seems to overestimate the peak discharge. If this value were used as the goal to guarantee HI, the result would be an underestimation of the compensatory measure to implement.

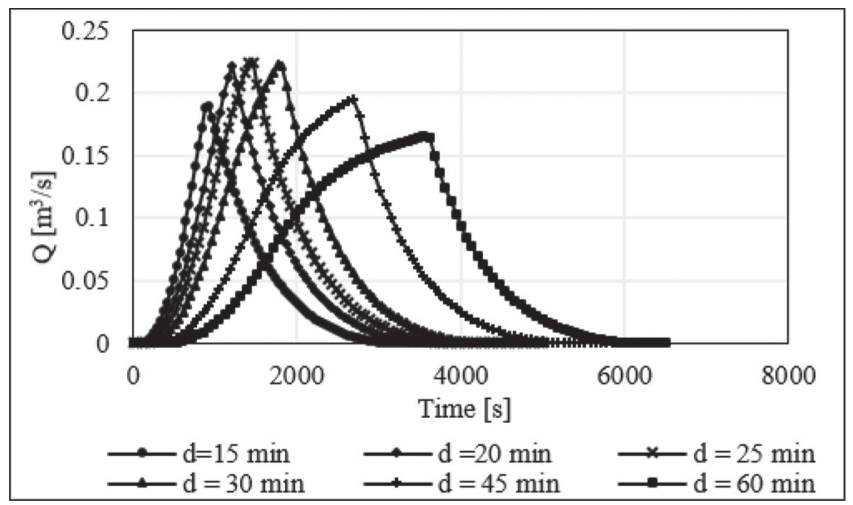

Figure 3: Hydrograph for several rainfall duration $\mathrm{K}=10^{-6} \mathrm{~m} / \mathrm{s} \mathrm{i}=0.05 \% \sigma=0$.

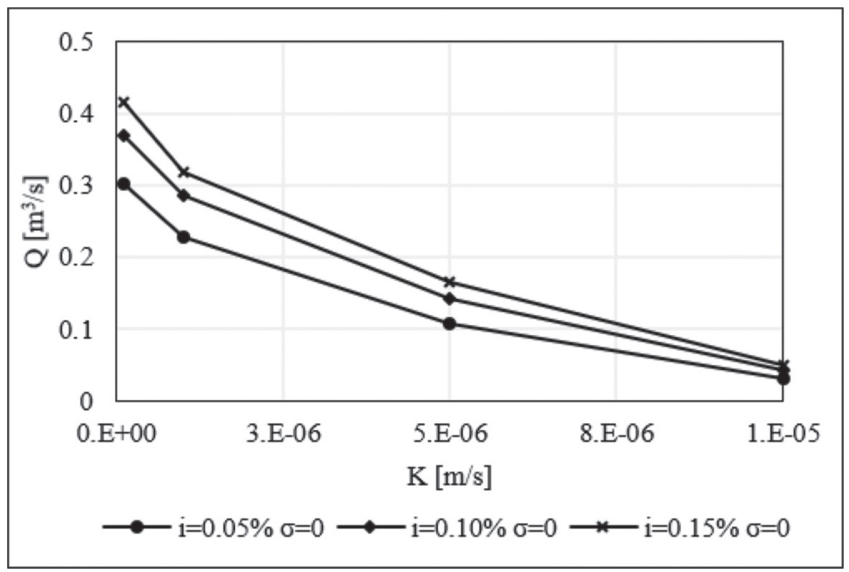

Figure 4: Q-K graph for different slope and constant Std Dev = 0 . 


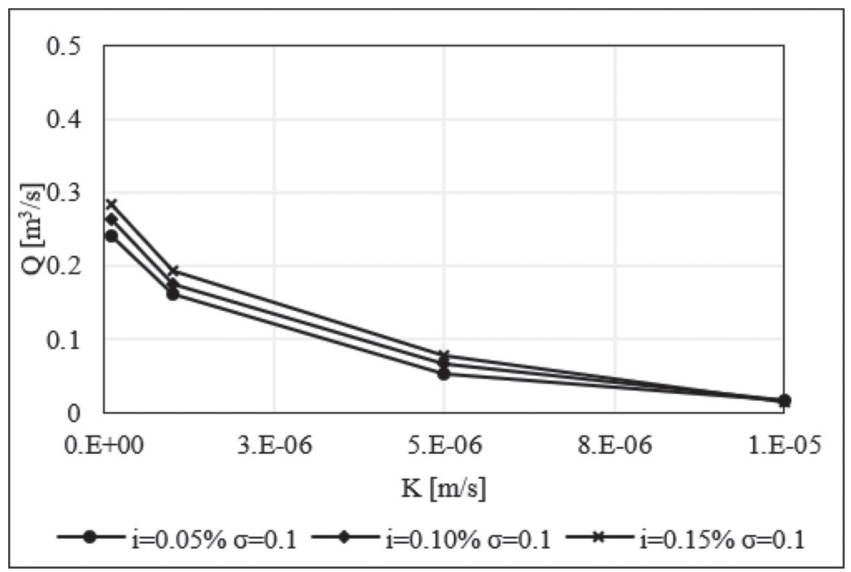

Figure 5: Q-K graph for different slope and constant Std Dev = 0.1.

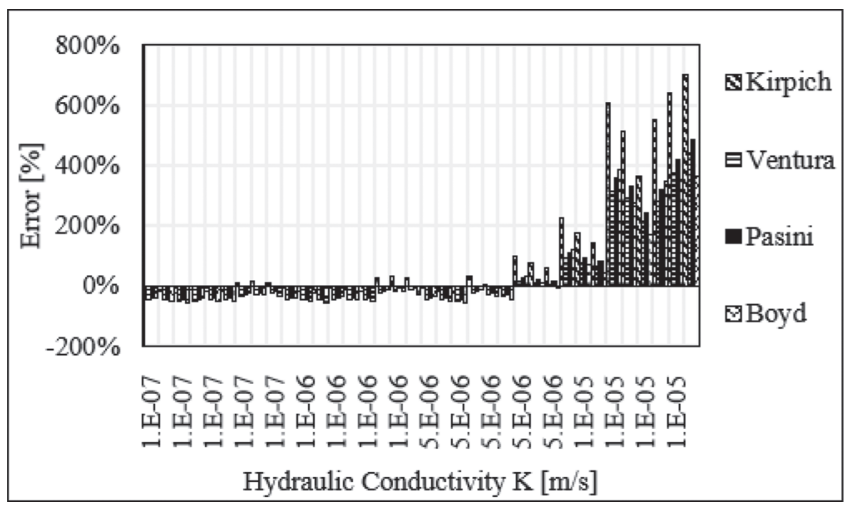

Figure 6: Differences (\%) between the Q value from FullSWOF and rational equation.

\section{INTERPOLATING RESULTS}

Unlike what is described in literature, where the concentration time is mainly correlated with the extension of drainage area, here an interpolating law for the critical rainfall duration has been derived as a function of permeability, slope, and ground standard deviation. At this aim a multiple regression has been carried out using an Excel worksheet. A good fit with coefficient of determination $\mathrm{R}^{2}=0.9$ has been obtained with the following equation:

$$
d_{c r}=b+m_{1} K_{n}+m_{2} \sigma_{n}+m_{3} K_{n}^{2}+m_{4} K_{n} \sigma_{n}+m_{5} \sigma_{n}^{2}+m_{6} i_{n}
$$

Variables in eqns (8) are z-score normalized using mean and standard deviation.

Also, the interpolating law for peak discharge has been derived:

$$
Q_{\max }=b+m_{1} \log _{10} K+m_{2} i+m_{3} \sigma .
$$

The coefficient of determination in this case was $\mathrm{R}^{2}=0.92$. In order to evaluate the weight of each variable in eqn (9) the T-test method was applied. The results are showed in Fig. 7. 


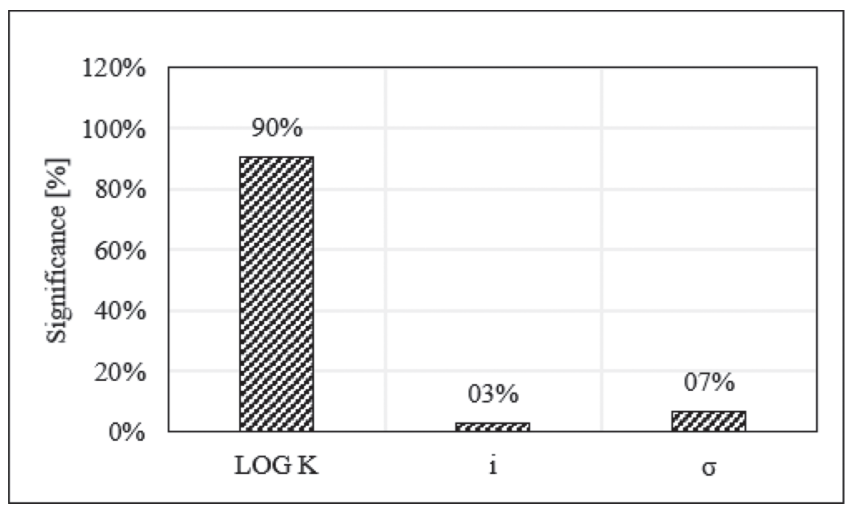

Figure 7: Weight percent of basin parameters on peak discharge formula.

The equations of the four coefficients of the hydrograph in eqn (3) have been derived:

$$
a, b, c, d=f\left(K, i, \sigma, t_{r}\right) .
$$

where $t_{\mathrm{r}}$ is the difference between the rainfall duration and the critical rainfall duration computed with eqn (8). Using eqns (10), valid within the Fiumicino area, the parametric hydrograph has been obtained. In terms of outflow volume, errors between parametric hydrographs and FullSWOF computed hydrographs are always less than $10 \%$.

Finally, an example comparing the water storage volume computed with the proposed method and the volume from not physically based approaches is shown in the follow. The ante operam and post operam conditions are listed below:

1. Initial condition: hydraulic conductivity $\mathrm{K}=10^{-5} \mathrm{~m} / \mathrm{s}$, mean slope $\mathrm{i}=0.05 \%$ standard deviation of ground elevation $\sigma=0$.

2. Final condition: hydraulic conductivity $\mathrm{K}=10^{-7} \mathrm{~m} / \mathrm{s}$, mean slope $\mathrm{i}=0.05 \%$ standard deviation of ground elevation $\sigma=0$.

The storage volume has been computed as the integral of the hydrograph exceeding the ante-operam peak flow. It depends on the rainfall duration, a function of the hydrograph coefficients a, b, c, d, which maximizes the previously mentioned volume. The volume computed with the proposed methodology is $\mathrm{v}=438.46 \mathrm{~m}^{3} / \mathrm{ha}$ and the corresponding rainfall duration is $\mathrm{d}=1.475$ hours (Fig. 8). The differences between this value and the results from not physically based approaches are shown in Fig. 9.

In conceptual model based HI methods, ante-operam peak flow has been computed with different formulation for the time of concentration. Runoff coefficient values both from literature and from FullSWOF simulations have been considered with the only exception of Pistocchi formula, which has been applied following Romagna basins' Authority indications, that is the weighted average between 0.9 for impervious areas and 0.2 for permeable areas. The comparison shows differences higher than $100 \%$. It is not possible to predict whether the literature methods are conservative or not.

It Fig. 10 and in Fig. 11 are shown the values of the volume required to obtain $\mathrm{HI}$ as a function of the maximum udometric coefficient allowed downstream comparing the results 


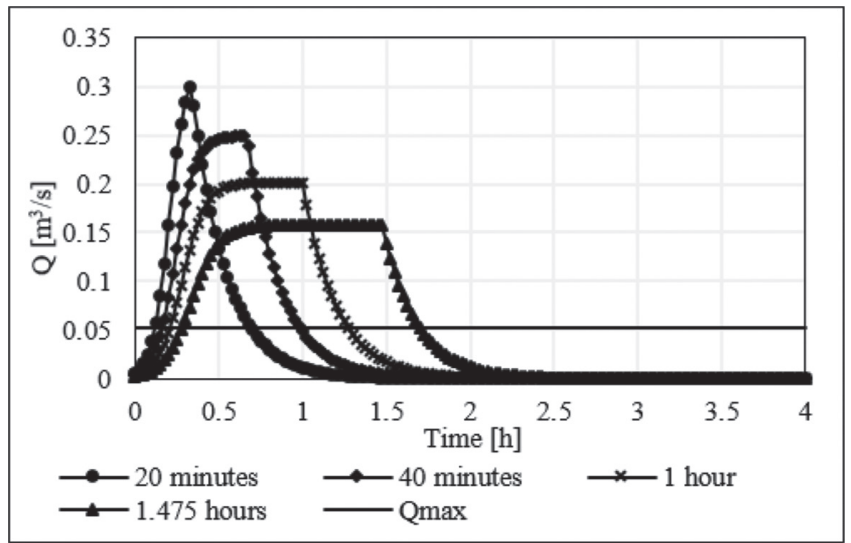

Figure 8: Dimensioning of water storage volume.

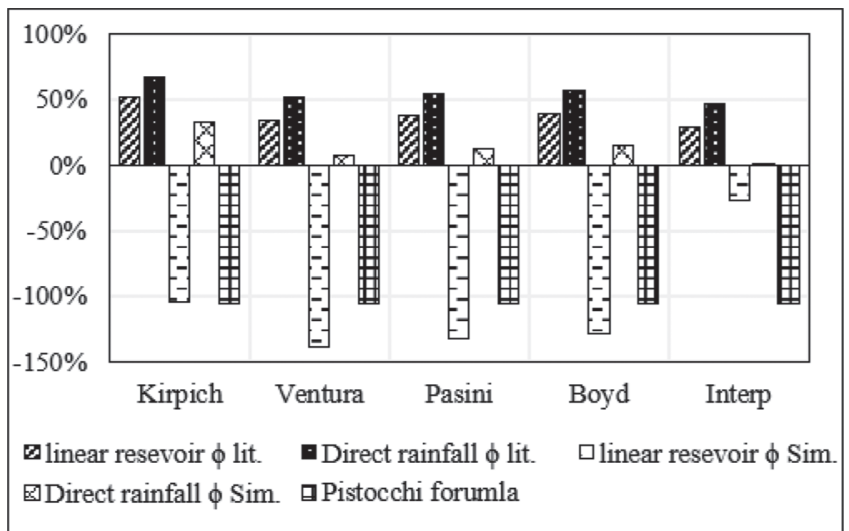

Figure 9: Differences $(\%)$ between the volume obtained with the method proposed and not physically based approaches.

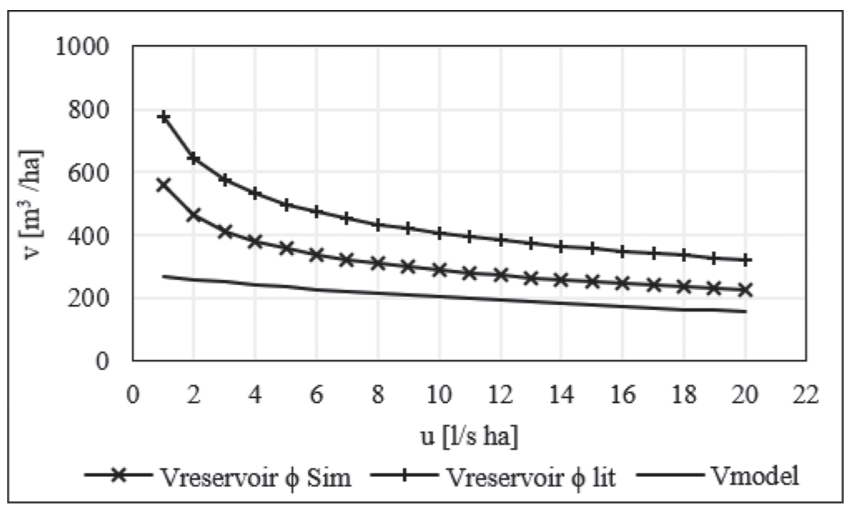

Figure 10: Comparison with Linear Reservoir Method $\mathrm{K}=10^{-6} \mathrm{~m} / \mathrm{s} \mathrm{i}=0.05 \% \sigma=0.1$. 


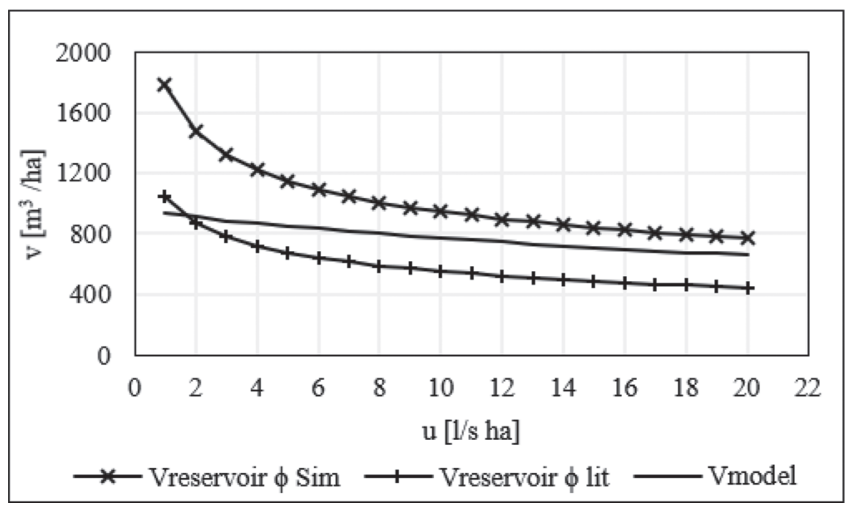

Figure 11: Comparison with Linear Reservoir Method $\mathrm{K}=10^{-7} \mathrm{~m} / \mathrm{s} \mathrm{i}=0.05 \% \sigma=0.0$.

obtained from the proposed method with those from the linear reservoir method, in which the runoff coefficient has been derived both from literature and FullSWOF simulations.

We can notice that in some cases the linear reservoir method gives for each udometric coefficient and for each runoff coefficient, the largest volume (Fig. 10). In other cases, for example considering runoff coefficient from literature, this method can significantly underestimate the volume for HI (Fig. 11).

\section{CONCLUSIONS}

In Italy the need to introduce measures of hydraulic invariance in urban planning has been felt due to the frequency of flash flooding events and to the high anthropization of the territory. In most of the regional laws or river basin authorities regulations, these measures consist in dimensioning appropriate storage volume, but they are still based on simple and not physically based methods. In order to fill this gap, in this paper a physically based approach to evaluate HI has been proposed. This consists in a storage routing method applied on a parametric hydrograph, defined by interpolating the results from a large number of hydraulic simulations carried out using the software FullSWOF.

Firstly, a comparison between the peak flow values obtained with FullSWOF simulations and with rational equation has been done. The differences were considerable, especially for pervious land cover, for which rational equation seems to overestimate the peak discharge. If this value were used as the goal to guarantee HI, this could result in an underestimation of the compensatory volume.

The simulations results have been also used to determine interpolating expressions for peak flow, for critical rainfall duration and for the four coefficients of the parametric hydrograph, valid within homogeneous sample area.

The storage routing of the parametric hydrographs have been carried out to calculate the volume requested by HI constraint. These volumes have been compared with the volumes obtained with the methods currently in use in Italy. The comparison has highlighted large differences, underlining how the results from the simplified approaches are strongly conditioned by the choice of the runoff coefficient.

\section{ACKNOWLEDGEMENTS}

This work has been supported by CREA, the Council for Agricultural Research and Economics, who provided pedological data of the test area of the municipality of Fiumicino. This 
dataset comes from the survey that CREA has carried out in cooperation with ARSIAL, the regional agency for agricultural development, with the purpose to draw up the soil map of Regione Lazio (SOILRELA research project).

\section{REFERENCES}

[1] Pistocchi, A., La valutazione idrologica dei piani urbanistici - Un metodo semplificato per l'invarianza idraulica dei piani regolatori generali. Ingegneria Ambientale, $\mathbf{X X X ( 7 / 8 ) , ~ p p . ~ 4 0 7 - 4 1 3 , ~} 2001$.

[2] Delestre, O., Darboux, F., James, F., Lucas, C., Laguerre, C. \& Cordier, S., FullSWOF: A free software package for the simulation of shallow water flows. Mapmo, université d'Orléans; Institut National de la Recherche Agronomique, 2014, available at https:// hal.archives-ouveres.fr/hal-00932234v2 (accessed 21 May 2015).

[3] Green, W.H. \& Ampt, G.A., Studies on soil physics. Part I. - the flow of air and water through soils. The Journal of Agricultural Science, 4(1), pp. 1-24, 1911. https://doi.org/10.1017/s0021859600001441

[4] Mein, R.G. \& Larson, C.L., Modeling infiltration during a steady rain. Water Resources Research, 9(2), pp. 384-394, 1973. https://doi.org/10.1029/wr009i002p00384

[5] Esteves, M., Faucher, X., Galle, S. \& Vauclin, M., Overland flow and infiltration modelling for small plots during unsteady rain: numerical results versus observed values. Journal of Hydrology, 228(3-4), pp. 265-282, 2000. https://doi.org/10.1016/s0022-1694(00)00155-4

[6] Hillel, D. \& Gardner, W.R., Transient infiltration into crust-topped profiles. Soil Science, 109(2), pp. 69-76, 1970. https://doi.org/10.1097/00010694-197002000-00001

[7] Delestre, O., Rain Water Overland Flow on Agricultural Fields Simulation, $\mathrm{PhD}$ thesis, University of Orléans, France, 2010.

[8] Audusse, E., Bouchut, F., Bristeau, M.-O., Klein, R. \& Perthame, B., A fast and stable well-balanced scheme with hydrostatic reconstruction for shallow water flows. SIAM Journal on Scientific Computing, 25(6), pp. 2050-2065, 2004. https://doi.org/10.1137/s1064827503431090

[9] Bouchut, F., Nonlinear Stability of Finite Volume Methods for Hyperbolic Conservation Laws, and Well-Balanced Schemes for Sources. Frontiers in Mathematics. Birkhäuser Basel, 2004.

[10] Rawls, W.J. \& Brakensiek, D.L., Green-Ampt infiltration parameters from soil data. Journal of Hydraulic Engineering, 109(1), pp. 62-70, 1983. https://doi.org/10.1061/(asce)0733-9429(1983)109:1(62)

[11] Brevnova, E.V., Green-Ampt Infiltration Model Parameter Determination Using SCS Curve Number (CN) and Soil Texture Class, and Application to the SCS Runoff Model, degree thesis, West Virginia University, West Virginia, 2001. 